\title{
Oral Corrective Feedback and Its Impact on Learners' Speaking Skills: Tunisian EFL Students as a Case Study
}

\author{
Ounis Tesnim \\ English Department, Faculty of Letters and Humanities of Sfax, University of Sfax, Sfax, Tunisia \\ Email address: \\ otesnim@yahoo.fr

\section{To cite this article:} \\ Ounis Tesnim. Oral Corrective Feedback and Its Impact on Learners' Speaking Skills: Tunisian EFL Students as a Case Study. International \\ Journal of Language and Linguistics. Vol. 7, No. 3, 2019, pp. 138-149. doi: 10.11648/j.ij11.20190703.15
}

Received: April 3, 2019; Accepted: May 11, 2019; Published: June 12, 2019

\begin{abstract}
The present research paper tries to discover the effect of teachers' oral corrective feedback (OCF) on EFL learners' speaking skills (grammar, vocabulary, pronunciation, and fluency). The study relies on the use of an experimental design and direct observations. 20 participants formed the experimental group. All subjects are intermediate foreign language learners of English (EFL). They are given an initial pre-test. Then, this experimental group undergoes intensive oral corrective feedback (mainly through prompts, recasts and explicit correction) delivered by their teacher during various oral activities. Finally, a post-test is applied. The analysis of the pre-test and post-test scores of the experimental group both quantitavely and qualitatively (using the MELA-Scoring Matrix) and the calculation of the mean rate of errors pre 100 words shows that learners' progress in oral performances vary from one individual to another. The findings of this study reveal that immediate and explicit OCF was able to positively affect EFL learners' grammatical development; yet, it was not helpful to ameliorate the learners' utterances in terms of vocabulary, fluency and pronunciation.
\end{abstract}

Keywords: Oral Corrective Feedback, Immediate Corrective Feedback, Intermediate EFL Learners, Speaking Skills

\section{Introduction}

The role of corrective feedback (CF) in language learning and teaching has gained much attention among researchers and it has become a highly controversial issue, especially with the shift of focus from language forms to language functions [1]. CF broadly refers to the teacher's reaction that transforms, disapproves or demands improvement of the learner's utterance [2]. The issue of the effectiveness of $\mathrm{CF}$ has been the source of considerable controversy in the past decades. The proponents embrace the necessity of CF in supporting and consolidating foreign language learning since it can match the learners' utterance with its corresponding version in the target language and draw the learners' attention to structures that have not been mastered [3], thus setting off a learning process. However, opponents maintain that changes in the learner's competence can only be initiated by primary linguistic data, not by corrective feedback [4]. They even advocate the idea of abandoning corrective feedback altogether in classroom interaction to avoid subsequent problems [5]. In Krashen' $\mathrm{s}$ [6] view error correction is a serious mistake because; first, it puts learners on the defensive and second, it only supports the development of learned knowledge and plays no role in acquired knowledge.

Many researchers have tackled the notion of teachers' feedback from different perspectives and have examined its influence on the acquisition of knowledge as well as the teaching of second/foreign language (such as: [7-13]). Feedback can be oral or written and it actually includes various types such as positive vs. negative, corrective vs. non-corrective, immediate vs. delayed, and explicit vs. implicit. For the purpose of this study, my focus is on oral corrective feedback as an intricate type of the teachers' treatment of learners' inaccuracy during communicative activities. I precisely seek to explore its contribution in the endorsement and the development of EFL learners' speaking skills.

\section{Theoretical Framework}

\subsection{Definition of Oral Corrective Feedback}

Lightbown and Spada [14] perceive that corrective feedback indicates to the learners a misuse or an incorrect 
form of the target language. This includes various responses that learners receive. According to Lightbown and Spada (as cited in [15]: 967), corrective feedback refers to "any indication to the learners that their use of the target language is incorrect". Calsiyao [16] define oral corrective feedback as "a means of offering modified input to students which could consequently lead to modified output by the students" ( $p$. 395). Likewise, Chaudron (as cited in [17]), defined "oral corrective feedback as any reaction of the teacher which clearly transforms, disapprovingly refers to, or demands improvement of the learner utterance" (p. 64). In short, oral corrective feedback is the process of giving correction toward student's error in oral production which can be conveyed by teachers. Therefore, it can be delivered explicitly through grammatical explanation or overt error correction or implicitly through metalinguistic information.

According to Lyster and Ranta [18], corrective feedback episodes consist of a trigger, the feedback move and (optionally) uptake. Uptake refers to a learner's observable immediate response to the corrective feedback in his/her utterances. [18] put forward that "student's utterance that immediately follows teacher's feedback and that constitutes a reaction in some way to the teacher's intention to draw attention to some aspects of the students' initial utterance" (p. 49). Likewise, Lyster and Llinares [19] define uptake as "a discourse move and not as an instance of acquisition, although some researchers have suggested that uptake may be 'related to learners' perceptions about feedback at the time of feedback" (p. 182). As such, the various forms of student responses subsequent to feedback, either as utterances with repair of the non-target items or as utterances still in need of repair, constitute the learner's uptake.

The question of Which errors to correct during oral classroom activities is highly important. In fact, EFL teachers are expected to differentiate between the different types of errors before providing oral corrective feedback. Corder [20] for instance, clarified that teachers should correct errors but not mistakes. He argued that an error occurs as a result of lack of knowledge (i. e. it is systematic) while a mistake occurs when a learner fails to perform his competence. According to Burt [21], there should be a distinction between global and local errors, and teachers should privilege providing $\mathrm{CF}$ on global errors which affect the overall sentence organization (e. g. wrong word order, missing or wrongly placed sentence connectors, and syntactic overgeneralizations), over local errors which affect single elements in a sentence (e. g. errors in morphology or grammatical functions). Hendrickson [22] states that there is no need to correct local errors arguing that the meaning is understandable and teacher's correction may only disrupt the course of communication, whereas global errors need to be corrected by the teacher in a certain way because the message delivered by the learner is ambiguous and incomprehensible. OCF strategies consist of explicit vs. implicit corrective feedback and input-providing vs. output-prompting corrective feedback.

Furthermore, it is worth noting that scholars have been reluctant to provide a fixed set of OCF strategies that teachers should follow during oral performance, as they are recognize the relative effectiveness of strategies and the striking complexity of the process of correcting errors which involves a number of competing factors. SLA researchers, on the other hand, have proposed a number of claims about which type of corrective feedback leads to language acquisition and learning. According to Long [23] recasts provide learners with the correct target forms in a context that establishes form-meaning connections and are nonintrusive that's to say do not interrupts the flow of communication which is important for learning the target language. In the same vein, Seedhouse [24] affirms that direct unmitigated repair by the teacher make errors unimportant and embarrassing, and thus it is preferred to resort to recasts. Output-prompting strategies, according to Lyster [25], enable learners to increase control over linguistic forms that they have partially acquired. Ellis, Loewen and Erlam' study [26] confirms that both implicit and explicit OCF are conducive to language learning. It is also important to know How to use those corrective feedback strategies during oral activities. In this context, Harmer [27] affirms that responses to oral production errors should be dealt differently and delicately, because they depend on the phase of the lesson, the type of tasks, the kind of error made, and certainly on students' personalities and their degree of knowledge.

Fluency and accuracy play a crucial role in oral production since they ensure a better understanding and eliminate misunderstanding. Therefore, it is important to provide a distinction between accuracy and fluency in speaking prior to specifying the significance of corrective feedback during accuracy- based and fluency-based activities. Concerning fluency, Richards et al. [28] point out that, in second and foreign language teaching, fluency designates "a level of proficiency in communication, which comprises the following points: the ability and ease in producing written and/or spoken language, the ability to speak with a good but not necessarily perfect control of intonation, vocabulary and grammar, the ability to communicate ideas effectively, and the ability to produce continuous speech without causing comprehension difficulties or a breakdown of the communication" (p. 141). [28] further add that fluency is mostly used in contrast with accuracy, which is "the ability to produce grammatically correct sentences but may not include the ability to speak or write fluently" (p.63). Noncommunicative activities according to [27] are meant to enhance the accuracy of learners, whereas communicative activities are intended to develop the fluency of learners. It is conceivable to think that the teacher, along the accuracy work, is expected to correct as well as to point out errors made by students. During communicative activities, learners negotiate meaning to try different modes of expression, which is very valuable in language learning.

As a logical culmination of this reasoning, corrective feedback during oral activities depends on how it is done (strategies), who it is done to (the learner), and when it is 
done (timing). In addition, as it is a very personal matter, correction draws much on the relationship between teachers and learners; in other words, correction must not frustrate or irritate learners. Kyriacou [29] propose the concept of supportive feedback, which denotes constructive and helpful feedback. This kind of correction is expected to sustain and encourage progress in learning new items and rules of language. It should be noted also that such supportive feedback exposes to the learners their troubles with language use. It is essentially a non-threatening feedback and the teacher should create a balance among individuals, groups, and peer feedback.

\subsection{How to Conduct Oral Corrective Feedback}

Various researchers have looked for the most effective method to treat the malformed utterances produced by learners, precisely the global errors. Bailey [30], cited in Brown [31], provided seven options to error correction, while each option could possibly have eight features. These options include "to treat or to ignore, to treat immediately or to delay, to transfer treatment or not, to transfer to another individual, a subgroup or the whole class, to return or not to the original error maker after treatment, to permit other learners to initiate correction, and to test for the efficacy of the treatment". The possible features are "fact of error indicated, location indicated, opportunity for new attempt given, model provided, error type indicated, remedy indicated, improvement indicated, and praise indicated" ([31], p. 238). Brown [32] asserts that teachers have to develop a kind of intuition to choose the appropriate option or a blend of options at the right moment. This intuition could be nurtured through experience, practice, and through considering the principles of cognitive feedback in Reinforcement Theory and Communicative Language Teaching (CLT).

Moreover, there exist a series of stages that teachers are expected to take into consideration in order to seize the needed options. First, they have to identify the type of error, that is, whether the error made is lexical, syntactic, phonological, or grammatical. Next, teachers should envisage the source of that error; for instance, the source of error might be the first language, i. e. transfer [33]. They also have to be knowledgeable of the linguistic complexity for further explanation of the error. After this stage, teachers should discriminate between global and local error, as well as mistake and error. They also should take into consideration the nature of the communicative context (group work, pair work or student-student, student-teacher exchange) and the style of correction, i. e. whether the teacher is interventionist, direct or indirect corrector. Brown [34] maintains that these stages and options seem a bit challenging but after a while teachers can use them automatically, and get the intuition easily. Once this intuition is achieved, then the teacher can easily identify the most correction-sensitive learners and act accordingly as a result [35]. It is worthy to take into consideration the affective state and linguistic stage of the individual learner. For some learners, for example, according to-[35], correction may cause distraction, stress, anxiety and tension.

\subsection{The Timing of Providing Oral Corrective Feedback}

EFL Teachers are faced with the choice of either correcting immediately following the learner's erroneous utterance or delaying the correction until later. Their decision depends on whether the activity is accuracy-based (correctting immediately) or fluency-based (correcting later). Hedge [36] proposes techniques for delaying corrective feedback that are either recording an activity and then asking students to identify and correct their own errors or simply noting down errors as students perform an activity and going through these afterwards.

Concerning the immediate oral corrective feedback, Doughty [37] maintains that any correction or a change in learners' inter-language corrective feedback has to occur in a window of opportunity and to attract roving attention to form while the learner's focal attention remains on meaning, whereas delayed corrective feedback engrosses focal attention on form leading to an explicit rather than implicit L2 knowledge.

In order to correct, Harmer [27] states that the teacher should intervene as late as possible. Yet, he argues that, when the teacher notices that the learners' communication is likely to fail, he should provide correction or propose alternatives. However, Ellis, Basturkmen and Loewen [38] state that the claim that immediate corrective feedback inevitably disrupts fluency work is probably not justified. Similarly, Dabaghi [39] insists that there is no evidence to show that immediate correction is more efficient and fruitful than the delayed type. It is to be inferred then that there is no final conclusion about the convenience of immediate and delayed corrective feedback.

\subsection{Taxonomy of Corrective Feedback}

Tedick \& Gortari [40] consider explicit corrective feedback as "clearly indicating that the student's utterance was incorrect, the teacher provides the correct form" (p. 2). Following Lyster and Ranta's [18] original taxonomy, CF types were classified as recasts, explicit correction, and prompts (what Lyster and Ranta called negotiation of form: i. e, clarification requests, repetition of error, elicitation, metalinguistic clues).

A. Prompts:

Prompts only provide corrective feedback. They "include a variety of signals, other than alternative reformulations, that push learners to self-repair" (Lyster and Saito [41], p. 152). They include the following types:

a. Clarification requests

Clarification requests indicate to the student that their utterance has been misunderstood or ill-formed and as a result a repetition or a reformulation is required. The teacher indicates that the message has not been understood or that the student's utterance included of a mistake and that a repetition or a reformulation is needed by using phrases like "Pardon me?" [18] (p. 47). Tedick \& Gortari [40] affirm that through “using phrases like „Excuse me? ?e $^{\text {ee }}$ „I don't understand teacher indicates that the message has not been understood or 
that the student's utterance contained some kind of mistake and that a repetition or a reformulation is required" (p. 03).

b. Repetition

According to Lyster and Ranta [18] repetition occurs when the teacher repeats in isolation the learner's ill formed or erroneous utterance. The teacher repeats the student's error with changes in intonation in order to draw speaker's attention to it. For example:

$\mathrm{S}$ : How much money do you have in your/pakit/?T: /pakit/? DS: /pokit/T: yes

c. Elicitations

The teacher explicitly asks questions that aim at eliciting the correct form from the learner. According to Tedick \& Gortari [40], elicitation occurs when "the teacher directly elicits the correct form from the student by asking questions (e. g, "How do we say that in French?") (p. 03), by pausing to allow the student to complete the teacher's utterance (e. g, "It's a....") or by asking students to reformulate the utterance (e. g, "Say that again.")". Elicitation is when the teacher repeats a learner's utterance up to the mistake with a rising intonation, signaling to the speaker that he/she should presume the utterance repairing the malformed error. It could also be a raised eyebrow or some gesture that indicates there is something that needs correction.

\section{B. Recasts}

It is generally realized through a repetition of content in a grammatically correct way. In other words, it takes the form of a paraphrase of a learners' incorrect utterances that involves replacing one or more of the incorrect components with a correct form while maintaining the meaning [18]. In this respect, Tedick \& Gortari [40] affirm that "without directly indicating that the student's utterance was incorrect, the teacher implicitly reformulates the student's error, or provides the correction" (p. 2).

In the classroom context, EFL teachers can deliver recasts in a number of ways:

a. They may or may not include prosodic emphasis on the problematic form.

b. They may be performed with rising intonation (i.e. as a confirmation check) or with falling intonation (i.e. as a statement).

c. They may be partial (i. e. reformulate only the erroneous segment in the learner's utterance) or complete (i. e. reformulate all of it). They may involve correcting just one or more than one feature.

Thus, depending on the particular way the recast is realized, it may be implicit or much more explicit. A recast then is a technique used in language teaching to correct learners' errors without hampering communication.

Recasts are used to correct errors related to plural form, indefinite articles...etc. They may involve correcting just one or more than one feature, depending on the particular way the recast is implemented; i. e. implicitly or explicitly. Lyster and Ranta [18] defined recasts as "the teacher's reformulation of all or part of a student's utterance, minus the error" (p.46). Recasts provide positive evidence and possibly also negative evidence.

\section{Explicit correction}

Tedick \& Gortari [40] state that explicit Correction refers to "clearly indicating that the student's utterance was incorrect, the teacher provides the correct form" (p. 02). Therefore, it includes a direct and clear indication and treatment of the ill-formed utterances.

\section{Methodology}

\subsection{Research Question}

This present study seeks to answer the following question:

How the various explicit types of OCF that are immediately delivered by EFL teachers during oral activities, affect learners' speaking skills (grammar, vocabulary, fluency and pronunciation)?

\subsection{The Purpose of the Study}

This study aims at discovering:

Whether EFL teacher's oral corrective feedback positively affects and endorses the development of speaking skills, or not; relying on a case study which I carried out on a group of intermediate Tunisian EFL learners to assess their oral production in relation to oral corrective feedback contribution.

\subsection{Participants}

Because this research deals with teachers' feedback and learners' performances, the presence of teachers and learners as participants is vital. The population consists of three Tunisian teachers of English: one teacher who participates in the experiment and the other two teachers play the role of raters; and one group of 1 st year university students. The group is composed of twenty students, aged approximately 20 with Arabic as their mother tongue, and who studied French as a second language and English as a foreign language. It could also be of interest to mention that none of the students suffered from any articulatory problems. The students were chosen at random, and included males and females with different levels of language proficiency.

Concerning the choice of the teachers, I selected them according to their basic branch of study, which is linguistics; because they are more acquainted with oral skills and communicative activities and were more familiar with the concepts of language acquisition and linguistic development. They were asked to score the students' oral performances using MELA-O Scoring Matrix after exposure to OCF. For the sake of ethics and privacy, I made it clear to both students and teachers that all the video-recordings included in this research would not mention their names or any personal details about them.

\subsection{Procedure and Data Collection Tools}

This research relies on experimental design. The results of the experiment were analyzed and interpreted both quantitatively and qualitatively. One of the typical 
benchmarks of the experimental design is the use of the pretest-post-test design. Thus, the principle of the experiment in this study is to assign the same test in those phases for a better assessment of each participant's degree of change from pre- to post-test. In fact, pre-tests and post-tests are effective techniques used to compare the initial and final scores of the participants. They facilitate the measurement of the efficiency of using different types of explicit OCF and to account for any kind of improvement or impairment. In addition, the experimental group was subject to OCF treatment sessions which lasted six months during various speaking activities (oral presentations, discussion/debate and role-play). The teacher provided several explicit corrective strategies (following the taxonomy proposed by Lyster and Ranta [18]) as immediate responses to their learners' utterances that contained elements to be modified, deleted or corrected.

Oral presentations about the topic of "Working as a parttime job while studying" serve as the test on the basis of which pupils are scored in the pre-test and the post-test. In order to compare the results of the tow tests, quantitative analysis was carried out through the calculation of the mean rate of errors (per 100 words) detected in the participants' utterances in pre and post test, as well as the calculation of the participants' scores in accordance with the MELA-O scoring matrix. In this respect, testing the learners' speaking performances in the light of their teacher's oral corrective feedback is restricted to the following set of evaluation criteria related to production skills (Grammar, Vocabulary, Fluency, and Pronunciation).

In addition, direct classroom observations, which served to qualitative analysis, were used to discover the link between EFL learners' oral performances and the true value of oral corrective feedback. Also, they helped me to see how participants tend to react to the various types of oral corrective feedback and how seriously they consider those negative remarks in their future presentations, as well as to account for classroom variables that may influence the process of providing OCF. Given the importance of videorecording for both quantitative and qualitative analysis, I recorded students' oral performances during oral activities and oral presentations (test) in order to see how the same performance is assessed before and after the implementation of OCF. So, I made use of a camera, a mobile phone and a computer in order to record and download the videos. The experimental group of twenty subjects was followed up over six-months, and was video-taped during oral sessions. This technique enabled me, as a researcher, to scrutinize and to assess not only the participant s' oral linguistic performances but also their different physical reactions to the teacher's OCF.

To summarize, the students' spontaneous speeches were collected at monthly intervals in the classroom. The oral presentations, which included the topic delivered by the teacher, were initially used in the experiment as a pretest. Then, after many practices and oral activities fuelled with immediate and explicit OCF, participants were asked to re- conduct the same topic of the oral presentation that is employed as a posttest. Once I transcribed and analyzed the linguistic features embedded in the participants' speeches (in pre-and post-test to calculate scores), I tried to determine the influence of OCF and their linguistic development at the level of grammar, vocabulary, fluency and pronunciation, through applying the MELA - $\mathrm{O}$ scoring Matrix and the calculation of the mean number of errors per 100 words.

\section{Results and Discussion}

The quantitative examination of the EFL learners' oral performances as a result of their teacher's oral corrective feedback can be dealt with by measuring their scores in grammar, vocabulary, fluency and pronunciation through applying the MELA - O scoring Matrix.

\subsection{Grammar}

Grammar refers to the set of rules that govern the way in which linguistic units, such as words and phrases, are combined to produce sentences in a given language. It also concerns the rules of pronunciation, inflection and syntax (verb tenses and subject-verb agreement...etc).

Table 1. Students' scores in grammar in pre and post-test.

\begin{tabular}{ll|l}
\hline & Scores in pre-test & Scores in post-test \\
\hline participant 1 & 2 & 2 \\
participant 2 & 1 & 3 \\
participant 3 & 3 & 5 \\
participant 4 & 2 & 2 \\
participant 5 & 3 & 3 \\
participant 6 & 4 & 4 \\
participant 7 & 2 & 4 \\
participant 8 & 3 & 4 \\
participant 9 & 1 & 2 \\
participant 10 & 1 & 2 \\
participant 11 & 4 & 5 \\
participant 12 & 1 & 3 \\
participant 13 & 2 & 3 \\
participant 14 & 4 & 5 \\
participant 15 & 3 & 4 \\
participant 16 & 2 & 5 \\
participant 17 & 3 & 5 \\
participant 18 & 2 & 4 \\
participant 19 & 2 & 3 \\
participant 20 & 2 & 4 \\
\hline
\end{tabular}

Table 1 shows that it is rather impossible to find a sophomore with poor grammatical competence. In fact, participants in this study has a certain background knowledge of the basic rules of English grammar rules such as sentence structure and word order, for none was marked nil, as the above-table indicated in this respect.

In the pretest, four participants demonstrated poor grammatical use as they were only able to produce some memorized structures and word-order forms. Their excessive use of formulaic speech negatively affected their verbal performances. However, after exposure to diverse communicative activities like discussion-debate and role-play accompanied by immediate oral corrective negative feedback 
from their teacher and meant to re-adjust and fix their grammatical deficiencies, those participants' performances steadily improved toward using more basic grammatical patterns correctly in simple, familiar phrases and sentences. Consequently, they showed clear progress in the post-test as they moved from level one to levels two and three.

Eight participants, who belonged to level two in the pretest, as it is shown in table 1, used familiar grammatical structures and very simple sentences. Only six students out of eight showed improvement. The problem with the two remaining learners is that their oral production did not reveal any significant improvement although they received corrective feedback as the other participants. The speech of the six participants, who showed a progress toward levels three, four and five in the post-test, displayed a tendency to use complex sentences. Their speech was also characterized by minor grammatical errors, and was generally fairly correct.

In the pre-test, five participants showed an ability to use grammar correctly with failed attempts to produce complex sentences. After exposure to their teacher's immediate corrective feedback, which targeted their failure toward producing correctly complex grammatical sentences (e. g. differences between relative and subordinate clauses), they were able to progress toward levels four and five as it is revealed is post-test results. It is to be noted that only one participant did not show any progress in his speech.

In the post test, two out of three showed a transition from level four to level five and one participant was stable at level four. Being subject to oral corrective feedback through explicit forms, those two students showed a remarkable enhancement in grammar. Accordingly, 16 participants out of 20 demonstrated a highly remarkable grammatical improvement in their speech production. It is to be noted that this improvement was the result of their directed attention and interest to their teacher's corrective feedback, which was included in the various oral activities as discussion-debate carried out between the pre and post-test. Yet, four students remained stable, that is to say their speech and responses were devoid of any kind of progress.

Table 2. Mean number of errors per 100 words in Grammar.

\begin{tabular}{lll}
\hline & $\begin{array}{l}\text { Number of errors per } \\
\text { 100 words in pre-test }\end{array}$ & $\begin{array}{l}\text { Number of errors per } \\
\text { 100 words in post-test }\end{array}$ \\
\hline participant 1 & 5 & 1 \\
participant 2 & 7 & 3 \\
participant 3 & 10 & 5 \\
participant 4 & 15 & 6 \\
participant 5 & 6 & 2 \\
participant 6 & 3 & 0 \\
participant 7 & 2 & 0 \\
participant 8 & 9 & 9 \\
participant 9 & 1 & 0 \\
participant 10 & 8 & 1 \\
participant 11 & 3 & 2 \\
participant 12 & 1 & 1 \\
participant 13 & 5 & 5 \\
participant 14 & 4 & 2 \\
participant 15 & 2 & 1 \\
participant 16 & 2 & 0 \\
\hline
\end{tabular}

\begin{tabular}{lll}
\hline & $\begin{array}{l}\text { Number of errors per } \\
\text { 100 words in pre-test }\end{array}$ & $\begin{array}{l}\text { Number of errors per } \\
\mathbf{1 0 0} \text { words in post-test }\end{array}$ \\
\hline participant 17 & 8 & 8 \\
participant 18 & 5 & 4 \\
participant 19 & 6 & 2 \\
participant 20 & 5 & 3 \\
$\begin{array}{l}\text { Mean number of } \\
\text { errors per 100 } \\
\text { words }\end{array}$ & $x=5.35$ & $x=1.9$ \\
\hline
\end{tabular}

Table 2 shows the mean results for grammar, i. e, number of errors for each 100 words both in the pre and post tests. The mean number of errors per 100 words in the pre-test $(x=5.35)$ largely exceeded the mean number of errors in the post -test for the same group $(x=1.9)$. This difference in error rate between the two tests was statistically significant: after exposure to teacher's oral corrective feedback, the rate of errors in grammar detected in the participant's speech notably diminished. It is to be noted that most of grammatical errors were repaired through prompts, i. e. through clarification requests, repetitions and elicitation. The teacher opted for these types of OCF because such types require much effort from the participants to reflect on their erroneous parts and to produce the correct output. It especially targeted the following forms: regular and irregular past tense corrected through clarification requests (e. g, participant A: "the student goed" / teacher comments: "You need past tense") rather than as explicit correction (e. g, "No, not goed went), through repetition (e. g. participant B: "While they are study". Teacher: "are study!!/study" (the teacher gives OCF with a special emphasis (rising intonation) and repeating the ungrammatical item.). As a response, participant reformulates: "While they are studying"; and through elicitation (e. g. participant: "some students worked eh eh two times in a week.". Teacher: "some students worked" (with rising intonation, rising eyebrows and using the two fingers to insist on the reformulation of the 'two'). The participant reformulates his utterance and says: "some students worked twice a week." ". Also, OCF was delivered through recasts. E. g, the participant: "working while studying causes many problems" the teacher interferes immediately: "emm causes (with rising intonation to draw the student's attention to the corrected word) many problems. Metalinguistic feedback also prompted learners' attention to the existence of grammatical errors and to the correct target forms. Schmidt [42] states that attention "is necessary in order to understand virtually every aspect of second language acquisition" (p. 01).

This result further outlines and reinforces the facilitative effect of OCF on the acquisition of grammatical forms. Indeed, the teacher's oriented corrective feedback through prompts (i. e. clarification requests, repetition, elicitations) and explicit correction can help the students overcome their grammatical deficiencies, since it serves to help them noticing the error they committed. Thus, participants were able to produce English words appropriately and speak in the right structure. Thanks to their teacher's explicit correction, they become familiar with some error types related to 
grammatical construction, the use of appropriate grammar rules, and they succeeded to avoid the same error in their next practices (the post-test). This finding echoes similar studies conducted by Sarwar [43], as well as Kosar and Bedir [44] that maintained the importance of corrective feedback in promoting grammar.

\subsection{Vocabulary}

Vocabulary refers to a student's understanding and appropriate use of the components of language that convey information and/or meaning. The smallest unit of meaning in a language is called a "lexeme," or lexical item, which may either be a single word ("book"), or a suffix ("-s"), or a prefix ("re-"). In addition, this dimension of the MELA-O Scoring Matrix includes the understanding of compound words and idioms.

Table 3. Students' scores in vocabulary in pre and post-test.

\begin{tabular}{lll}
\hline & Scores in pre-test & Scores in post-test \\
\hline participant 1 & 3 & 3 \\
participant 2 & 2 & 2 \\
participant 3 & 3 & 4 \\
participant 4 & 3 & 3 \\
participant 5 & 3 & 3 \\
participant 6 & 3 & 4 \\
participant 7 & 2 & 2 \\
participant 8 & 4 & 5 \\
participant 9 & 1 & 1 \\
participant 10 & 3 & 3 \\
participant 11 & 3 & 3 \\
participant 12 & 2 & 2 \\
participant 13 & 1 & 1 \\
participant 14 & 5 & 5 \\
participant 15 & 2 & 3 \\
participant 16 & 3 & 4 \\
participant 17 & 3 & 3 \\
participant 18 & 2 & 2 \\
participant 19 & 3 & 4 \\
participant 20 & 4 & 5 \\
\hline
\end{tabular}

According to table 3, seven participants out of twenty showed improvement as it is revealed in the post-test results. It is to be noticed that the majority of the pupils who improved ( 6 out of seven) belonged to levels three and four; those learners already have a good vocabulary background, an ability to engage in communicative activities and they displayed a flow of speech that was rarely interrupted by inappropriate use of lexical items. This enhancement in their vocabulary production was detected in their ability to produce and rephrase ideas and thoughts to express the meaning they wanted to convey.

However, seventeen participants remained stable in their levels and did not improve. In fact, even after exposure to their teacher's oral corrective feedback, their speeches displayed excessive use of fragmented vocabulary which implies a difficulty to understand the meanings of some words and they often misused words in a particular context.

It can be deduced that although OCF seem to be helpful in improving the vocabulary of some students who are already equipped with "good" vocabulary background, it did not show efficiency in enhancing and enriching the vocabulary of learners with fair (or poor) vocabulary. Therefore, EFL teachers are expected to make more attention to the individual learner who is making errors.

Table 4. The Mean number of errors per 100 words in vocabulary.

\begin{tabular}{lll}
\hline & $\begin{array}{l}\text { Number of errors per } \\
\text { 100 words in post-test }\end{array}$ & $\begin{array}{l}\text { Number of errors per } \\
\text { 100 words in post-test }\end{array}$ \\
\hline participant 1 & 7 & 6 \\
participant 2 & 4 & 3 \\
participant 3 & 3 & 1 \\
participant 4 & 2 & 0 \\
participant 5 & 6 & 5 \\
participant 6 & 5 & 4 \\
participant 7 & 3 & 2 \\
participant 8 & 2 & 1 \\
participant 9 & 7 & 7 \\
participant 10 & 7 & 7 \\
participant 11 & 9 & 8 \\
participant 12 & 3 & 2 \\
participant 13 & 3 & 3 \\
participant 14 & 2 & 2 \\
participant 15 & 5 & 5 \\
participant 16 & 1 & 0 \\
participant 17 & 7 & 7 \\
participant 18 & 8 & 8 \\
participant 19 & 6 & 6 \\
participant 20 & 2 & 2 \\
Mean number of & & $x=4$ \\
errors per 100 & $x=4.6$ & \\
words & &
\end{tabular}

Table 4 exposes the mean number of errors in vocabulary both in the pre-test and post-test. There is a little change in the mean number of errors between the two tests. For the pretest, the rate of errors per 100 words is $(x=4.6)$, which slightly surpasses the rate of errors in the post-test $(x=4)$; in other words the rate of errors detected in the participants' speeches in the post-test did not significantly improved after the students' exposure to their teacher's corrective feedback through clarification requests, repetitions, elicitation, and explicit correction which were endorsed during the different oral activities held between the two tests. As such, oral corrective feedback delivered immediately and explicitly did not help the majority of EFL learners to enrich or enlarge their vocabulary knowledge. It was observed that many participants still suffer from inappropriate use of vocabulary.

\subsection{Fluency}

Fluency refers to the degree to which spoken language appears smooth, effortless, and natural. The qualities of language that contribute to fluency include native-like use of pausing, rhythm, intonation, emphasis, rate of speaking, and use of interjections and interruptions. In second language teaching, fluency refers to the ability to produce continuous speech without causing comprehension difficulties or a breakdown of communication. Sometimes confused with accuracy, fluency refers to the flow of language rather than to its correctness. 
Table 5. Participants' scores of fluency in pre and post-test.

\begin{tabular}{lll}
\hline & Scores in pre-test & Scores in post-test \\
\hline participant 1 & 2 & 3 \\
participant 2 & 3 & 3 \\
participant 3 & 2 & 2 \\
participant 4 & 4 & 5 \\
participant 5 & 2 & 2 \\
participant 6 & 3 & 3 \\
participant 7 & 1 & 2 \\
participant 8 & 4 & 4 \\
participant 9 & 2 & 2 \\
participant 10 & 2 & 3 \\
participant 11 & 3 & 4 \\
participant 12 & 2 & 3 \\
participant 13 & 2 & 3 \\
participant 14 & 3 & 3 \\
participant 15 & 2 & 3 \\
participant 16 & 2 & 1 \\
participant 17 & 2 & 1 \\
participant 18 & 1 & 2 \\
participant 19 & 2 & 2 \\
participant 20 & 2 & 2 \\
\hline
\end{tabular}

Table 5 shows that two participants who belonged to level one in the pre-test results became part of level two in the post-test results. This transition from one level to another comes as a result of their teacher's corrective feedback which was used as a treatment for fluency deficiencies between the two tests. Yet, this transition does not mark a significant improvement of fluency. In fact, the post-test results did not exhibit a remarkable development which implies that the majority of the participants did not benefit from their teachers' OCF. Their utterances were characterized by poor fluency displayed especially in their fragmented utterances and frequent resort to fixed verbal formulae, and inability to create new sentences.

Twelve participants belonged to level two in the pre-test as their speech was full of stock sentences and long pauses. Repeated hesitation is also a common phenomenon in their speech. The post-test results showed that only four participants out of twelve improved towards levels three, whereas eight students remained within the same level since their speech was devoid of any hints of enhancement in fluency.

Four participants were classified in level three in the pretest results as table 5 shows. Only one participant improved towards levels four. In general, the participants' utterances did not show a major fluency during the post-test. Instances of occasional lapses and hesitations while searching for the correct manner of expression and frequent hesitations still mark their speeches. Table 5 also shows that two participants belonged to level four. One student improved to reach level five whereas the other one remained stable within the same level.

Accordingly, it can be deduced from comparing the pre and post-test results that lower than the half of the participants (eight out of twenty) progressed in their fluency, which implies that OCF enacted during various oral activities did not contribute to endorsing learners' fluency. This result questions the impact of this type of feedback on the development of fluency. Based on the classroom observations, the timing of providing OCF which was mostly immediate and explicit, and the nature of classroom discourse which was obviously dominated by the teacher can explain the failure of OCF in supporting fluency enhancement.

Table 6. The Mean number of errors per 100 words in fluency.

\begin{tabular}{lll}
\hline & $\begin{array}{l}\text { Number of errors per } \\
\text { 100 words in pre-test }\end{array}$ & $\begin{array}{l}\text { Number of errors per } \\
\text { 100 words in pre-test }\end{array}$ \\
\hline participant 1 & 4 & 4 \\
participant 2 & 3 & 2 \\
participant 3 & 7 & 7 \\
participant 4 & 1 & 1 \\
participant 5 & 3 & 2 \\
participant 6 & 2 & 1 \\
participant 7 & 6 & 5 \\
participant 8 & 8 & 8 \\
participant 9 & 11 & 11 \\
participant 10 & 10 & 10 \\
participant 11 & 4 & 2 \\
participant 12 & 4 & 4 \\
participant 13 & 6 & 6 \\
participant 14 & 3 & 2 \\
participant 15 & 1 & 1 \\
participant 16 & 3 & 3 \\
participant 17 & 3 & 2 \\
participant 18 & 4 & 4 \\
participant 19 & 7 & 7 \\
participant 20 & 10 & 10 \\
Mean number of & $x=5$ & $x=5$ \\
errors per 100 words & $x$ & \\
\hline
\end{tabular}

Table 6 presents the mean number of errors both in the pre and post-test. The results clearly prove evidence that the rate number of errors found in the participants' speech in the post-test $(\mathrm{x}=5)$ is the same as in the post-test. This result implies that even though learners were subject to teacher's oral corrective feedback, which was meant to treat and to correct their dis-fluency problems, their utterances were not significantly improved in terms of fluency. These results show that Tunisian EFL students did not benefit from their teacher' OCF targeting their fluency deficiencies.

Although, EFL teachers' error correction has the power of improving the students' levels (as in the case of grammar), in some other situations it cannot have a positive or significant influence on oral fluency practice. Therefore, it seems that excessive focus on error correction leaves no opportunities for learners to speak, to practice and to improve their oral fluency which is the main goal of speaking.

Based on the observations, it was obvious that during communicative activities immediate and frequent teachers' correction interrupted the students, disturbed them and decreased their opportunities to practice their oral fluency. The main conclusion to be drawn from this part is that teachers' oral corrective feedback affects negatively learners' oral fluency practice.

It is advisable that teacher's intervention through OCF to treat learners' performances should depend on the types of errors made, and the type of activity. In this vein, Harmer [45] observes that if the teachers correct whenever there is a 
difficulty, the flow of communication as well as the purpose of the speaking activity will be damaged [45]. If EFL learners are frequently and instantly corrected, they may become demotivated and unwilling to take risks and speak. Baker \& Westrup [46] suggested that EFL teachers remedy learners' errors positively and focus more on offering them opportunities to communicate and cooperatively interact.

\subsection{Pronunciation}

Pronunciation refers to the student's proficiency in producing sound, or a group of sounds, in order to convey meaning. Pronunciation includes the intonation, rhythm, emphasis, and juncture (pauses) of a language. For MELA-O matrix, pronunciation focuses primarily on the intelligibility, or perception, of the sounds by the listener, rather than on the "articulation" or production of actual speech sounds in the mouth.

Table 7. Students' scores of pronunciation in pre and post-test.

\begin{tabular}{lll}
\hline & Scores in pre-test & Scores in post-test \\
\hline participant 1 & 3 & 4 \\
participant 2 & 2 & 2 \\
participant 3 & 3 & 4 \\
participant 4 & 2 & 2 \\
participant 5 & 2 & 2 \\
participant 6 & 3 & 4 \\
participant 7 & 2 & 3 \\
participant 8 & 4 & 4 \\
participant 9 & 2 & 2 \\
participant 10 & 3 & 3 \\
participant 11 & 3 & 3 \\
participant 12 & 2 & 2 \\
participant 13 & 2 & 2 \\
participant 14 & 4 & 4 \\
participant 15 & 3 & 3 \\
participant 16 & 2 & 2 \\
participant 17 & 3 & 4 \\
participant 18 & 3 & 4 \\
participant 19 & 3 & 3 \\
participant 20 & 3 & 4 \\
\hline
\end{tabular}

The results of table 6 show that seven participants were scored to level two in terms of their fluency according to the MELA-O scoring Matrix. These participants displayed a frequent resort to their first language, which is in this study Arabic. At this level, the participant's pronunciation was clearly influenced by the first language sounds and intonation patterns. In most of the cases, they were compelled to repeat their utterances in order to be understood. The post-test results reveal also that one participant improved and reached levels three and six participants, who belonged to level three, improved toward level four. Yet, more than half of the total population of the participants (12) did not show instances of development. Added to that, none of the participants showed improvement toward level five. This implies the difficulty to reach this level because broadly EFL pupils' speeches, pronunciation and intonation were influenced by their L1.

Overall, the results show that six participants out of twenty improved slightly in pronunciation. At some extent, they become able able to speak understandably with some sounds but still affected by their first language. They frequently use first language intonation patterns, but are generally understood. This little development detected in the pronunciation of some EFL pupils comes after extensive oral activities accompanied with OCF from their teachers. This feedback was designed to repair participants' problems in pronunciation and especially to help them overcome the influence of their first language.

Table 8. The Mean number of errors per 100 words in pronunciation.

\begin{tabular}{lll}
\hline & $\begin{array}{l}\text { Number of } \\
\text { errors per 100 } \\
\text { words in pre-test }\end{array}$ & $\begin{array}{l}\text { Number of errors } \\
\text { per 100 words in } \\
\text { pre-test }\end{array}$ \\
\hline participant 1 & 2 & 2 \\
participant 2 & 1 & 1 \\
participant 3 & 7 & 7 \\
participant 4 & 0 & 0 \\
participant 5 & 1 & 1 \\
participant 6 & 0 & 0 \\
participant 7 & 4 & 4 \\
participant 8 & 7 & 7 \\
participant 9 & 11 & 11 \\
participant 10 & 8 & 8 \\
participant 11 & 2 & 2 \\
participant 12 & 1 & 1 \\
participant 13 & 6 & 6 \\
participant 14 & 0 & 0 \\
participant 15 & 0 & 0 \\
participant 16 & 1 & 1 \\
participant 17 & 0 & 0 \\
participant 18 & 0 & 0 \\
participant 19 & 3 & 3 \\
participant 20 & 8 & 8 \\
Mean number of errors per & $x=3$ & \\
100 words & & \\
\hline
\end{tabular}

Table 8 clarifies mean rate of errors calculated in the two tests. The pre-test and the post-test results display the same mean number of errors $(x=3)$, that is to say the number of errors detected in the participants' speeches was not decreased after exposure to OCF. This result implies that EFL students seem not take benefit from the accentuated corrective feedback delivered by their teacher and designed to correct pronunciation troubles (between the 2 tests), as such there was no remarkable advance or progress in their pronunciation. This result also entails the failure of corrective feedback in the process of phonological treatment that is likely to be due to the following reason: whenever the participants faced a difficulty, the teacher stopped them and corrected the errors, in this case the teachers' oral corrective feedback automatically turns off the communication and turns on the study of language form.

Overall, the findings of this research underscore the inefficiency of the immediate treatment of learners' errors by the excessive correction. Similar study conducted by Littlewood [47] confirms that excessive corrections alters leaner's focus from meanings to forms, and urges teachers to abandon structural correction, or postpone it until after the oral activity. The same view is shared by Lindsay and Knight [48] who put forward the disadvantages of immediate treatment that can break the flow of communication and 
demotivate or embarrass students. Harmer [27] calls for not focusing on correcting structural errors during communicative activities since this interrupts the communication and drags an activity back to the study of language forms. As such, EFL teachers should pay strict attention to which errors to correct, when and how to correct. Johnson [49] states that "error correction really is a medicine where an overdose can kill" (p. 337).

Besides, the affective factors mostly render the process of OCF more complex and delicate. In fact, when systematically corrected, many participants may feel worried about making errors, become increasingly afraid of criticism or losing face and they become very stressed and shy because of mispronouncing words. In this context, Littlewood [47] and Park \& Lee [50] maintain that inhibitions and anxiety are easily created in a foreign language classroom where error correction is endorsed and directed to repair oral performance.

\section{Conclusion}

The analysis yields the following conclusions associated with different types of corrective feedback in L2 classrooms: prompts, and explicit correction. Some of the EFL students who participated in this study succeeded in overcoming their errors in the post-test and showed different degrees of improvement, specifically in terms of grammar. Therefore, immediate and explicit OCF was able to positively affect EFL learners' grammatical development, as the participants improved and the number of errors detected in their utterances decreased after exposure to their teacher's corrective feedback in the various oral activities.

However, this was not the case with the other three components of speaking skills which are vocabulary, fluency and pronunciation. EFL students' levels were slightly improved and the rate of errors detected in the post-test results was not enhanced compared to that of the pre-test results. It can be therefore deduced that immediate and explicit oral corrective feedback was not helpful to ameliorate the learners' utterances in terms of vocabulary, fluency and pronunciation; this result can be related to a number of overlapping problems:

a. The timing of delivering OCF (which is in this study immediate OCF) caused problems like:

b. Learners' nervousness, anxiety and fearfulness from mispronouncing words and losing face in front of their classmates. In this regard, Argudo [51] suggested that "teachers have to avoid corrective feedback because it likely has harmful impacts on students' affective domain" (p. 124).

c. Instant and frequent interruption of EFL learners may hurt their self-respect, which subsequently can diminish their willingness to speak and impede the flow of communication. Elsaghayer [52] who states, "feedback should always be personal, and never directed at person's personality" (p. 76).

d. Excessive focus on learners' accuracy at the expanse of their fluency and pronunciation. Focus on form practices, in the classroom context, hampers the process of developing learners' communicative skills.

e. EFL teachers tend to privilege the correction of local errors that target the grammatical functions, at the expanse of global errors.

f. EFL learners are likely to face negative transfer from their mother tongue

g. Enriching vocabulary orally is a very delicate task. It requires practices that go beyond focusing on explicit error correction. Many other researchers, for instance Dornyei (1995), advocate the teaching of communication strategies that allow EFL speakers to overcome communicative difficulties and enlarge their vocabulary knowledge especially through the instruction of paraphrase strategy.

\section{References}

[1] Brown, H. D. (2004). Language assessment: Principles and classroom practices. White Plains, NY: Pearson Education. Pp. 324

[2] Chaudron, C. (1977). A descriptive model of discourse in the corrective treatment of learners' errors. Language Learning, $27,29-46$.

[3] White, L. (1991). Adverb placement in second language acquisition: Some effects of positive and negative evidence in the classroom. Second Language Research. 7, 133- 161.

[4] Schwartz, B. (1993). On explicit and negative data effecting and affecting competence and linguistic behaviour. Second Language Research, 2, 120-1 59.

[5] Truscott, J. (1999). What's wrong with oral grammar correction. The Canadian Modern Language Review, 55, 437456.

[6] Krashen, S. (1985). The input hypothesis: Issues and implications. London: Longman.

[7] Mackey, A, Gass, S, \& McDonough, K. (2000). How do learners perceive interactional feedback? Studies in Second Language Acquisition, 22 (4), 471-497.

[8] Lyster, R. (2002). Negotiation in immersion teacher-student interaction. International Journal of Educational Research, $37,237-253$.

[9] Loewen, S. (2004). Uptake in Incidental Focus on Form in Meaning-Focused ESL Lessons. Language learning, 153-188.

[10] Sheen, Y. (2004). Corrective feedback and learner uptake in communicative classrooms across instructional settings. Language Teaching Research, 8 (3), 263-300.

[11] Hyland, K.\& Hyland, F. (2006). Feedback on Second Language students' writing. Language Teaching. 39 (2): 83101 .

[12] Sheen, Y, \& Ellis, R. (2011). Corrective feedback in language teaching. In E. Hinkel (Ed.), Handbook of research in second language teaching and learning (Volume II, pp. 593-610). New York: Routledge. 
[13] Lyster, R, Saito, K, \& Sato, M. (2013). Oral corrective feedback in second language classrooms. Language Teaching, $46(1), 1-40$.

[14] Lightbown, P. M. and Spada, N. (1999). How languages are learned? ( $2^{\mathrm{ND}}$ edition). Oxford. Oxford University press.

[15] Karbalaei, Alireza and Karimian, K. (2014). 'On the Effect of Type of Teacher Corrective Feedback on Iranian EFL Learners' Writing Performance'. Indian Journal. Sci. Res, 7 (1).

[16] Calsiyao, S. (2015). 'Corrective Feedback in Classroom Oral Errors among Kalinga- Apayao State College Students.' International Journal of Social Science and Humanities Research, 3/1: 135

[17] Mendez, E and Cruz, M. (2012). 'Teachers' Perceptions About Oral Corrective Feedback and Their Practice in EFL Classrooms.'ELT Journal, 14/2: 64.

[18] Lyster, R and Ranta, L. (1997). 'Oral Corrective Feedback and Student Uptake; Negotiation of Form in Communicative Classrooms.'SSLA. pp. 44- 55.

[19] Lyster, R and Llinares, A. (2014). 'The Influence of Context on Patterns of Corrective Feedback and Learner Uptake: a Comparison of CLIL and Immersion Classrooms.' The Language Learning Journal, 42 (2).

[20] Corder, P. (1967). The significance of learner's errors. International Review of Applied Linguistics, S, 161-170.

[21] Burt, M. (1975). Error Analysis in the Adult EFL Classroom. TESOL Quarterly, 9 (1), 53-63. doi: 10.2307/3586012

[22] Hendrickson, J. M. (1981). Error analysis and error correction in language teaching. Singapore: SEAMEO Regional Language Centre.

[23] Long, M. H. (2006). Problems in SLA. Mahwah, NJ: Lawrence Erlbaum.

[24] Seedhouse, P. (2004). The interactional architecture of the language classroom: A conversation analysis perspective. Malden, MA: Blackwell

[25] Lyster, R. (2004). Differential effects of prompts and recasts in form-focused instruction. Studies in Second Language Acquisition, 26, $399-432$

[26] Ellis, R, Loewen, S, \& Erlam, R. (2006). Implicit and explicit corrective feedback and the acquisition of L2 grammar. Studies in Second Language Acquisition, 28, 339-368

[27] Harmer, J. (2001). The practice of English language teaching. Essex: Pearson Education Limited.

[28] Richards, J. C, P. Tung \& P. Ng. (1992). The culture of the English language teacher: a Hong Kong example. RELC Journal, 23 (1), 81-102.

[29] Kyriacou, C. (1997). Effective Teaching in Schools, 2nd edition. Cheltenham: Nelson Thornes.

[30] Bailey, K. M. (1983). Competitiveness and anxiety in adult second language learning: Looking at and through the diary studies. In: H. W. Seliger, \& M. H. Long (Eds.), Classroom Oriented Research in Second Language Acquisition, pp. 67102. Rowley: Newbury House.

[31] Brown, H. D. (2001). Teaching by Principles: An Interactive
Approach to Language Pedagogy. New-York: Longman.

[32] Brown, D. H. (2000). Principles of language learning \& teaching. (4th ed.). New York: Longman. (pp. 49-58)

[33] Skinner, B. F. (1979). The Shaping of a Behaviorist: Part Two of an Autobiography. New York: Random House.

[34] Brown, G. T. L. (2011). Teachers' conceptions of assessment: Comparing primary and secondary teachers in New Zealand. Assessment Matters, 3, 45-70.

[35] Gregerson, T. S. (2003). To Err Is Human: A Reminder to Teachers of Language-Anxious Students. Foreign Language Annuls. Vol. 36. pp. 25-32.

[36] Hedge, T. (2000). Teaching and learning in the language classroom. United Kingdom. Oxford: Oxford University Press.

[37] Doughty, C. (2001). Cognitive underpinnings of focus on form. In P. Robinson (Ed.), Cognition and second language instruction (pp. 206-257). Cambridge: Cambridge University Press.

[38] Basturkmen, H, \& Loewen, S. (2001). Learner uptake in communicative ESL lessons. Language learning, 51, 281-318.

[39] Dabaghi, A. (2006). Error correction. Report on a study. Language Learning Journal, 34 (1): 10-13

[40] Tedick, J. 1998. Research on Error Correction and Implications for Classroom Teaching. Indiana: University of Minnesota

[41] Lyster, R, Saito, K, \& Sato, M. (2013). Oral corrective feedback in second language classrooms. Language Teaching, 46 (1), 1-40.

[42] Schmidt, R. (2001). Attention. In P. Robinson (Eds.), Cognition and second language instruction (pp. 3-32). New York: Cambridge University Press.

[43] Sarwar, M. Ashfaque, A. S. and MehlahJabeen. (2014). 'Assessing English Speaking Skills of Prospective Teachers at Entry and Graduation Level in Teacher.' Language Testing in Asia; A Springer Open Journal, 4/5: 1.

[44] Kosar, G. and Hasan Bedir. (2014). 'Strategies- Based Instruction: A means of Improving Adult EFL Learners' Speaking Skills.' International Journal of Language Academy, 2/3: 16- 17.

[45] Harmer, J. (1991). The practice of English language teaching. Longman Handbooks for Language Teachers. London/New York.

[46] Baker, J, \& Westrup, H. (2003). Essential speaking skills. London: Continuum and Voluntary Service Overseas.

[47] Littlewood, W. (2007). Communicative and task-based language teaching in East Asian classrooms. Language Teaching 40 (3), 243-249.

[48] Lindsay, C. \& Knight, P. (2006). Learning And Teaching English A Course For Teachers. New York: Oxford University Press.

[49] Johnson, K. (2008). Precision Teaching. In N. Suskind (ed.), The Encyclopedia of Educational Psychology, 2, 809-813. Thousand Oaks, CA: Sage Publications. 
[50] Park, H. \& Lee, A. R. (2005). L2 Learners' Anxiety; SelfConfidence and Oral Performance. Paper presented at The Pan-Pacific Association of Applied Linguistics (PAAL), Japan.

[51] Argudo, M. (2013). 'An Investigation Into How EFL Learners Emotionally Respond to Teachers' Oral Corrective Feedback.' Applied Linguistic Journal, 15/2: 124.
[52] Elsaghayer, M. (2014). 'Affective Damage to Oral Corrective Feedback among Students in Libyan Secondary Schools. IQSR Journal of Research \& Method in Education (IQSRJRME), 4/6: 76.

[53] Dornyei, Z. (1995). On the Teachability of Communication Strategies. TESOL QUARTERLY. Vol. 29, No. 1, 